\title{
SEOM clinical guidelines for the diagnosis and treatment of gastroenteropancreatic and bronchial neuroendocrine neoplasms (NENs) (2018)
}

\author{
E. González-Flores ${ }^{1} \cdot$ R. Serrano ${ }^{2} \cdot$ I. Sevilla $^{3} \cdot$ A. Viúdez $^{4} \cdot$ J. Barriuso $^{5,6} \cdot$ M. Benavent $^{7} \cdot$ J. Capdevila $^{8}$. \\ P. Jimenez-Fonseca ${ }^{9} \cdot$ C. López $^{10} \cdot$ R. Garcia-Carbonero ${ }^{11}$ (1)
}

Received: 28 October 2018 / Accepted: 7 November 2018 / Published online: 7 December 2018

(c) The Author(s) 2018

\begin{abstract}
NENs are a heterogeneous family of tumors of challenging diagnosis and clinical management. Their incidence and prevalence continue to rise across all sites, stages and grades. Although improved diagnostic techniques have led to earlier detection and stage migration, the improved prognosis documented over time for advanced gastrointestinal and pancreatic neuroendocrine tumors also reflect improvements in therapy. The aim of this guideline is to update practical recommendations for the diagnosis and treatment of gastroenteropancreatic and lung NENs. Diagnostic procedures, histological classification and therapeutic options are briefly discussed, including surgery, liver-directed therapy, peptide receptor radionuclide therapy, and systemic hormonal, cytotoxic or targeted therapy, and treatment algorithms are provided.
\end{abstract}

Keywords Guidelines $\cdot$ Neuroendocrine tumors $\cdot$ Neuroendocrine neoplasms $\cdot$ Gastroenteropancreatic $\cdot$ Lung $\cdot$ Diagnosis Therapy

R. Garcia-Carbonero

rgcarbonero@gmail.com

E. González-Flores

encarnagonzalezflores@gmail.com

R. Serrano

rsblanch@hotmail.com

I. Sevilla

isevilla02@yahoo.es

A. Viúdez

aviudez@outlook.es

J. Barriuso

begroj@gmail.com

M. Benavent

martabenaventv@gmail.com

J. Capdevila

jacapdevila@vhebron.net

P. Jimenez-Fonseca

palucaji@hotmail.com

C. López

clopez@humv.es

1 Department of Medical Oncology, Hospital Universitario Virgen de las Nieves, Granada, Spain

2 Department of Medical Oncology, Hospital Reina Sofía, Córdoba, IMIBIC, CIBERONC, Córdoba, Spain
3 Department of Medical Oncology, Instituto de Investigaciones Biomédicas de Málaga (IBIMA)/Hospitales Universitarios Regional y Virgen de la Victoria de Málaga, Málaga, Spain

4 Department of Medical Oncology, Complejo Hospitalario de Navarra (CHN), OncobionaTras Unit, Navarrabiomed, IdiSNA, Pamplona, Spain

5 Division of Cancer Sciences, School of Medical Sciences, Faculty of Biology, Medicine and Health, University of Manchester, Manchester, UK

6 Department of Medical Oncology, The Christie NHS Foundation Trust, Manchester, UK

7 Department of Medical Oncology, Hospital Universitario Virgen del Rocío, Instituto de Biomedicina, Seville, Spain

8 Department of Medical Oncology, Vall Hebron University Hospital, Vall Hebron Institute of Oncology (VIHO), Barcelona, Spain

9 Department of Medical Oncology, Hospital Universitario Central de Asturias, Oviedo, Spain

10 Department of Medical Oncology, Hospital Universitario Marqués de Valdecilla, Santander, Spain

11 Department of Medical Oncology, Hospital Universitario 12 de Octubre, IIS imas12, UCM, CNIO, CIBERONC, Av. de Córdoba, s/n, 28041 Madrid, Spain 


\section{Introduction}

The incidence of NENs has increased 6.4-fold over the past four decades, from 1.09 (1973) to 6.98 (2012) new cases per 100,000 inhabitants annually [1]. Per primary tumor site, the incidence rates were $3.56 / 10^{5}$ in gastroenteropancreatic (GEP), $1.49 / 10^{5}$ in the lung and $0.84 / 10^{5}$ in neuroendocrine tumors (NETs) of unknown primary site. Survival for all NENs has improved, particularly for distant-stage pancreatic and gastrointestinal NETs (panNETs and GINETs), although it widely varies by primary tumor site, proliferative index (ki67 or mitotic index), histological differentiation and stage $[1,2]$. According to the SEER data, rectum (24.6 years) and appendix ( $>30.0$ years) NETs had the best prognosis, while panNETs (3.6 years) and lung NETs (5.5 years) had the worst survival. Survival by grade also widely ranged from 16.2 and 8.3 years for grade G1 and G2 to 10 months for high-grade tumors. About $20-25 \%$ of NENs are functioning tumors, that is, they are associated with a clinical syndrome due to excessive hormone production (carcinoid syndrome, Zollinger-Ellison syndrome, etc.). This proportion is decreasing with time due to earlier diagnosis and improved symptomatic and antineoplastic therapy [3]. They are generally diagnosed in the fifth decade of life, and about $5 \%$ of them are associated with hereditary predisposition syndromes. NENs are therefore a complex, heterogenous family of tumors of challenging clinical management. In this manuscript, we aim to provide synthetical and practical guidelines regarding diagnostic procedures and therapeutic options for the multidisciplinary management of NENs of GEP or lung origin. Available medical literature was reviewed according to main topics of disease management and classified by scientific levels of evidence and grades of clinical recommendation (Table 1).

\section{Diagnostic procedures}

The diagnosis of NENs may require clinical, biochemical, pathological, radiological, nuclear medicine or endoscopic procedures, depending upon primary tumor site, tumor stage and clinical presentation including hormonal syndromes [3]. Besides a comprehensive medical history, physical examination and laboratory tests (including hematological, liver and renal function parameters), the following procedures are recommended for an adequate diagnosis of NENs:

- Chromogranin A (well-differentiated NETs) (III,B) or neuron-specific enolase (NSE) [poorly differentiated neuroendocrine carcinomas (NECs)] (I, C).

- Urinary 5-hydroxyindoleacetic acid (5-HIAA) (carcinoid syndrome); gastrin \pm secretin test (gastrinomas); insulin/ glucose ratio, proinsulin, $C$ peptide (insulinomas), glucagon, VIP and others depending upon clinical symptoms (IV, C).

- Histopathological report should include the WHO classification and TNM staging, as well as immunohistochemistry staining including ki67 and general neuroendocrine markers (chromogranin A, synaptophysin and NSE). Specific markers are not mandatory and should only be performed if clinically indicated (insulin, glucagon, etc.) (I, A).

- Somatostatin receptor imaging: ${ }^{68}$ Gallium-DOTA-TOC/NOC/-TATE positron emission tomography (PET) (preferred if available) or somatostatin receptor scintigraphy (octreoscan) [4] (III, B).

- Dynamic CT scan or MRI of the abdomen.

- Chest X-ray. A thoracic CT scan may be considered in poorly differentiated tumors, colon primaries or those in whom surgery of liver metastasis is being considered and is also mandatory in lung NENs.

Table 1 Levels of evidence and grades of recommendation

\begin{tabular}{|c|c|}
\hline Levels of evidence & Grades of recommendation \\
\hline $\begin{array}{l}\text { I. Evidence from at least one large randomized, controlled } \\
\text { trial of good methodological quality (low potential for } \\
\text { bias) or meta-analyses of well-conducted randomized tri- } \\
\text { als without heterogeneity }\end{array}$ & $\begin{array}{l}\text { A. Strong evidence for efficacy with a substantial clinical benefit, strongly } \\
\text { recommended }\end{array}$ \\
\hline $\begin{array}{l}\text { II. Small randomized trials or large randomized trials with a } \\
\text { suspicion of bias (lower methodological quality) or meta- } \\
\text { analyses of such trials or of trials with demonstrated } \\
\text { heterogeneity }\end{array}$ & $\begin{array}{l}\text { B. Strong or moderate evidence for efficacy but with a limited clinical benefit, } \\
\text { generally recommended }\end{array}$ \\
\hline III. Prospective cohort studies & $\begin{array}{l}\text { C. Insufficient evidence for efficacy or benefit does not outweigh the risk or the } \\
\text { disadvantages (adverse events, costs,...), optional }\end{array}$ \\
\hline IV. Retrospective cohort studies or case-control studies & $\begin{array}{l}\text { D. Moderate evidence against efficacy or for adverse outcome, generally not } \\
\text { recommended }\end{array}$ \\
\hline $\begin{array}{l}\text { V. Studies without control group, case reports, experts } \\
\text { opinions }\end{array}$ & E. Strong evidence against efficacy or for adverse outcome, never recommended \\
\hline
\end{tabular}


- Genetic counseling in hereditary predisposition syndromes (MEN-1, von Hippel-Lindau disease, tuberous sclerosis, and neurofibromatosis, among others).

Depending on the clinical presentation and site of the primary tumor, other evaluations such as endoscopic procedures, 18-Fluorodeoxyglucose-(FDG-) PET, N-terminal pro-brain natriuretic peptide (NT-pro-BNP) and echocardiogram (carcinoid syndrome), brain CT or bone scan may be performed.

\section{Classification and staging systems}

The 2010 WHO classification of digestive tumors is the most widely accepted classification of GINENs by the scientific community. It stratifies these tumors based on histological differentiation, ki67 and mitotic index into three major prognostic groups: G1 and G2 NETs and G3 NECs $[5,6]$. However, in 2017, the WHO classification of Endocrine Tumors was updated, and this includes panNETs but not GINETs. This subdivides G3 NENs into well-differentiated tumors (G3 NETs) and poorly differentiated carcinomas (G3 NECs) [7].

In NET of the lung, the 2015 WHO classification [8] is the most widely used, and defines four categories (typical carcinoid, atypical carcinoid, large cell NEC and small cell NEC) based on morphological features, the mitotic count and the presence of necrosis. The cutoff point of ki67 is under discussion and not required for tumor classification (Table 2 summarizes the main features of the WHO classification by tumor site).

Probably, the inclusion of genetic alterations in the different classifications may help in the future to further characterize and stratify the prognosis of NENs.

Local, regional and distant extent of disease should be classified according to the American Joint Committee on Cancer/Union for International Cancer Control (AJCC/ UICC) TNM staging system (8th edition).

\section{Therapy}

\section{Grade 1-2 GEP and bronchial NETs (Fig. 1a, b) (Table 3)}

\section{Surgery}

Surgery is the only potentially curative therapeutic strategy in these patients. Radical oncological surgery, even in cases with metastatic disease if complete resection is deemed feasible, is indicated except for small $(<1 \mathrm{~cm})$ carcinoids of the stomach, duodenum, appendix or rectum, and small pancreatic insulinomas, in which more conservative surgical or endoscopic resections may be appropriate given their low risk of metastasis [9]. No adjuvant therapy is recommended

Table 2 WHO classifications of pancreatic, gastrointestinal and lung neuroendocrine neoplasms

\begin{tabular}{|c|c|c|}
\hline $\begin{array}{l}\text { Pancreatic NENs } \\
\text { WHO } 2017\end{array}$ & $\begin{array}{l}\text { Gastrointestinal Tract NENs } \\
\text { WHO } 2010\end{array}$ & $\begin{array}{l}\text { Lung NENs } \\
\text { WHO } 2015\end{array}$ \\
\hline \multicolumn{3}{|l|}{ Well differentiated } \\
\hline $\begin{array}{l}\text { PanNET G1 ki67<3\%; } \\
<2 \mathrm{mit} / 10 \mathrm{HPF} \\
\text { PanNET G2 ki67 3-20\%; } \\
\text { 2-20 mit/10HPF } \\
\text { PanNET G3 ki67>20\%; > } 20 \mathrm{mit} / 10 \mathrm{HPF}\end{array}$ & $\begin{array}{l}\text { NET G1 ki67 } \leq 2 \% \text {; } \\
<2 \text { mit/10HPF } \\
\text { NET G2 ki67 2-20\% and/or } \\
2-20 \mathrm{mit} / 10 \mathrm{HPF}\end{array}$ & $\begin{array}{l}\text { Typical carcinoid } \\
<2 \mathrm{mit} / 10 \mathrm{HPF} \text {; no necrosis } \\
\text { Atypical carcinoid } \\
2-10 \mathrm{mit} / 10 \mathrm{HPF} \text { and/or foci of necrosis }\end{array}$ \\
\hline \multicolumn{3}{|l|}{ Poorly differentiated } \\
\hline $\begin{array}{l}\text { PanNEC G3 ki67> } 20 \%>20 \mathrm{mit} / 10 \mathrm{HPF} \\
\text { Small cell type } \\
\text { Large cell type }\end{array}$ & $\begin{array}{l}\text { NEC G3 ki67> } 20 \% \text { and/or }>20 \mathrm{mit} / 10 \mathrm{HPF} \\
\text { Small cell type } \\
\text { Large cell type }\end{array}$ & $\begin{array}{l}\text { NEC small cell type } \\
\text { (also combined small cell NEC) } \\
>10 \text { mitoses/10HPF } \\
\text { NEC large cell type } \\
\text { (also combined large cell NEC) } \\
>10 \text { mitoses/10HPF } \\
\text { Combined small cell NEC } \\
>10 \text { mitoses/10HPF }\end{array}$ \\
\hline
\end{tabular}

Mixed neuroendocrine

MiNEN: mixed neuroendocrine-nonneuroendo- $\quad$ MANEC: mixed adeno-neuroendocrine carcinoma crine neoplasm

The final grade is determined based on whichever index (Ki67 or mitotic) places the tumor in the highest grade category

PanNENs pancreatic neuroendocrine neoplasms, PanNET pancreatic neuroendocrine tumor, NET neuroendocrine tumor, NEC neuroendocrine carcinoma 
Fig. 1 a Therapeutic algorythm for G1-2 GEP NETs. b Therapeutic algorythm for typical and atypical Lung NETs
A

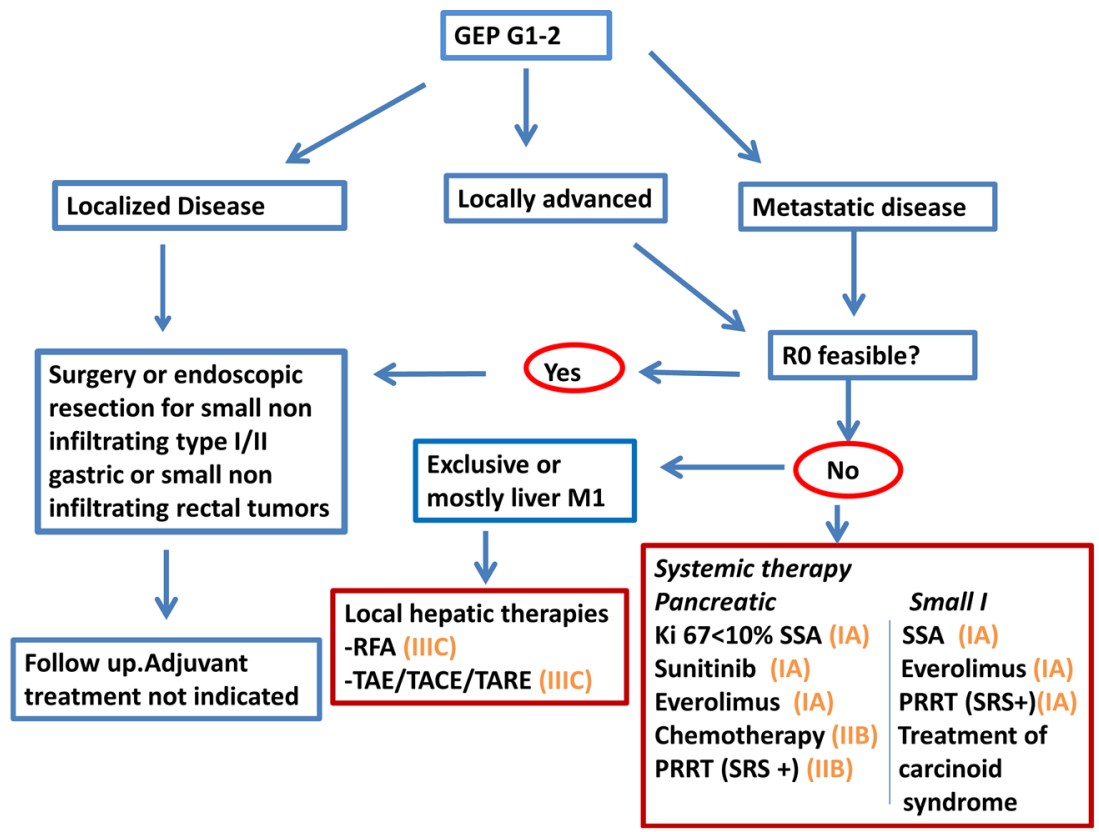

B
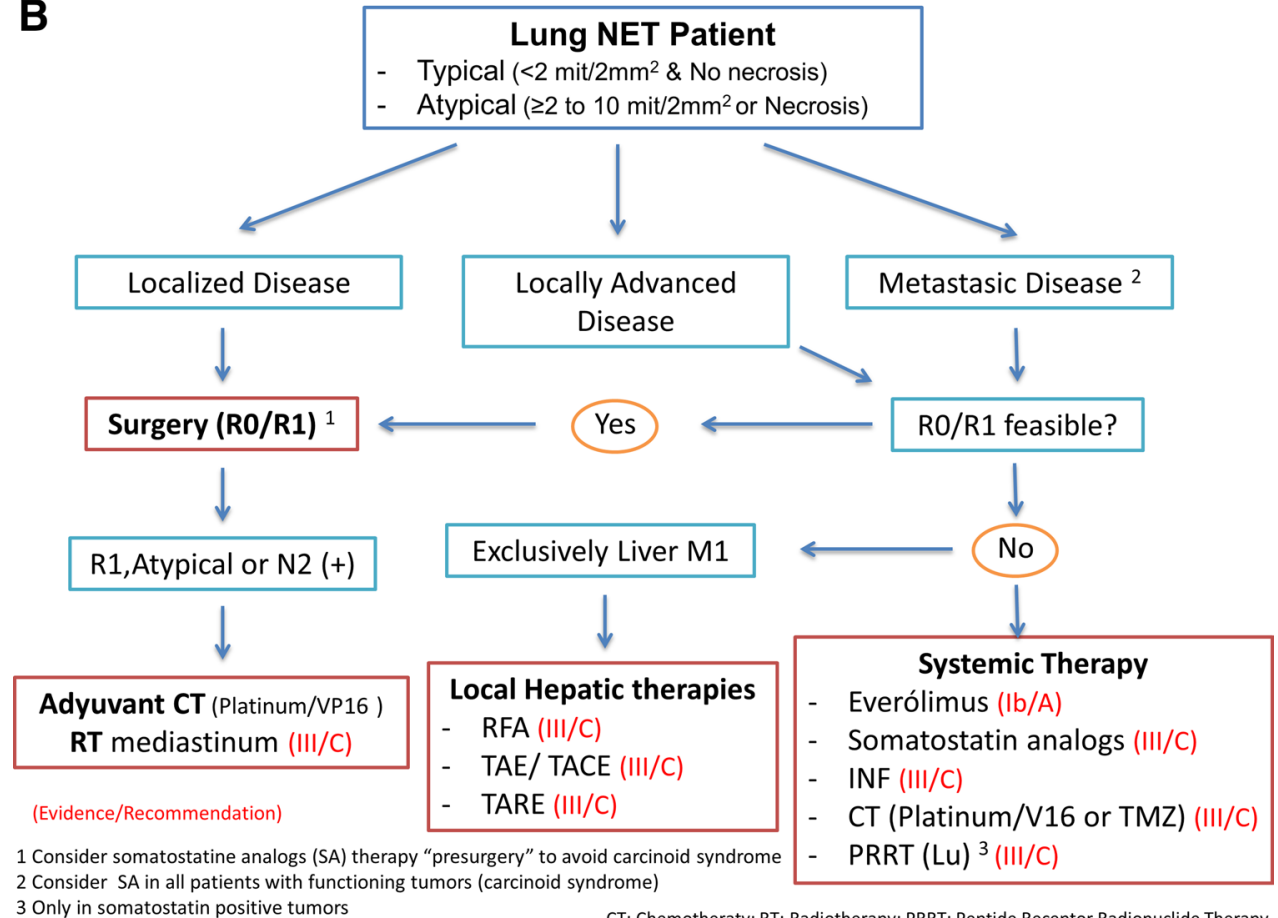

CT: Chemotheraty; RT: Radiotherapy; PRRT: Peptide Receptor Radionuclide Therapy after complete resection of well-differentiated (G1/G2) NETs (IV, C).

Major cytoreductive surgery with palliative purposes may be indicated when resection of $>90 \%$ tumor burden is feasible, especially for patients with hormonal syndrome refractory to medical therapy. Besides the significant clinical benefit in cases with functioning tumors, there are some retrospective data that suggest an impact in terms of survival [10] (IV, B).

In patients with unresectable metastatic disease, palliative surgery may be considered in cases with symptomatic primary tumor, mainly in patients with small bowel NETs. Perioperative prophylactic therapy with somatostatin analogues (SSA) is mandatory in functional tumors to prevent carcinoid crisis. Finally, liver transplantation is still controversial 
Table 3 Summary of randomized phase III trials of systemic therapy in G1-2 NETs (J. Capdevila)

\begin{tabular}{|c|c|c|c|c|}
\hline Study & $N$ & Schedule & Primary endpoint & Secondary endpoints \\
\hline $\begin{array}{l}\text { Moertel CG } \\
\text { [9] }\end{array}$ & 105 & $\begin{array}{l}\text { STZ+ DOXO vs. STZ+5FU vs. } \\
\text { Chlorozotocin }\end{array}$ & RR $69 \%$ vs. $45 \%$ vs. $30 \%$ & $\begin{array}{l}\text { mPFS } 20 \text { months (STZ-Doxo) vs. } \\
6.9 \text { months (STZ-5FU) } \\
\text { mOS } 2.2 \text { years (STZ-Doxo) vs. } 1.4 \text { years } \\
\text { (STZ-5FU) }\end{array}$ \\
\hline $\begin{array}{l}\text { PROMID } \\
{[15]}\end{array}$ & 85 & Octreotide LAR 30 mg vs. placebo & $\begin{array}{l}\text { TTP } 14.3 \text { months vs. } 6 \text { months; } \\
\text { HR } 0.34 ; 95 \% \text { CI } 0.20-0.59 \\
p=0.000072)\end{array}$ & \\
\hline $\begin{array}{l}\text { CLARINET } \\
{[16]}\end{array}$ & 204 & $\begin{array}{l}\text { Lanreotide Autogel } 120 \text { mg vs. } \\
\text { placebo }\end{array}$ & $\begin{array}{c}\text { mPFS } 32.8 \text { months vs. } 18 \text { months; HR } \\
0.47 ; 95 \% \text { CI } 0.30-0.73, p=0.001\end{array}$ & $\begin{array}{l}\text { Progression-free survival at } 24 \text { months: } \\
65.1 \% \text { vs. } 33 \%\end{array}$ \\
\hline $\begin{array}{l}\text { NETTER-1 } \\
{[24]}\end{array}$ & 229 & $\begin{array}{l}\text { 177Lu-Dotatate vs. octreotide LAR } \\
60 \mathrm{mg}\end{array}$ & $\begin{array}{l}\text { mPFS } 28.4 \text { months vs. } 8.5 \text { months; } \\
\text { HR } 0.214 ; 95 \% \text { CI } 0.139-0.331 \\
p<0.0001\end{array}$ & RR $18 \%$ vs. $3 \%$ \\
\hline SU1111 [21] & 171 & Sunitinib $37.5 \mathrm{mg}$ qd vs. placebo & $\begin{array}{l}\text { mPFS } 11.4 \text { vs. } 5.5 \text { months; HR } 0.42 \text {; } \\
\text { 95\% CI } 0.26-0.66, p<0.001\end{array}$ & $\begin{array}{l}\text { RR } 9 \% \\
\text { mOS } 38.8 \text { vs. } 29.1 \text { months; HR } 0.73 \text {; } \\
\quad 95 \% \text { CI } 0.50-1.06 ; p=0.094\end{array}$ \\
\hline $\begin{array}{l}\text { RADIANT-3 } \\
\text { [22] }\end{array}$ & 410 & Everolimus $10 \mathrm{mg}$ qd vs. placebo & $\begin{array}{l}\text { mPFS } 11.0 \text { vs. } 4.6 \text { months; HR } 0.35 \\
95 \% \text { CI } 0.27-0.45, p<0.001\end{array}$ & $\begin{array}{l}\text { RR } 5 \% \\
\text { mOS } 44 \text { vs. } 37.7 \text { months; HR } 0.94 ; 95 \% \\
\quad \text { CI, } 0.73-1.20 ; p=0.30\end{array}$ \\
\hline $\begin{array}{l}\text { RADIANT-4 } \\
\text { [23] }\end{array}$ & 302 & Everolimus $10 \mathrm{mg}$ qd vs. placebo & $\begin{array}{l}\text { mPFS } 11.0 \text { vs. } 3.9 \text { months, respec- } \\
\text { tively, HR } 0.48 ; 95 \% \text { CI } 0.35-0.67 \text {, } \\
p<0.00001\end{array}$ & $\begin{array}{l}\text { RR } 2 \% \\
\text { mOS not reached (HR } 0 \cdot 64 ; 95 \% \text { CI } \\
0 \cdot 40-1 \cdot 05 \text {, one-sided } p=0.037 \text {, } \\
\text { whereas the boundary for statistical } \\
\text { significance was } 0 \cdot 0002)\end{array}$ \\
\hline $\begin{array}{l}\text { RADIANT-2 } \\
\text { [9] }\end{array}$ & 429 & $\begin{array}{l}\text { Everolimus } 10 \mathrm{mg} \mathrm{qd}+\text { octreotide } \\
\text { LAR } 30 \mathrm{mg} \text { monthly vs. octreotide } \\
\text { LAR } 30 \mathrm{mg} \text { monthly }\end{array}$ & $\begin{array}{l}\text { mPFS } 16.4 \text { vs. } 11.3 \text { months; HR } 0.77 \text {, } \\
95 \% \text { CI } 0.50-1.00, p=0.026\end{array}$ & $\begin{array}{l}\text { RR } 2 \% \\
\text { mOS } 29.2 \text { vs. } 35.2 \text { months (HR } 1.17 \text {; } \\
\quad 95 \% \text { CI, } 0.92-1.49, p=\mathrm{ns})\end{array}$ \\
\hline
\end{tabular}

$N$ number of patients, $S T Z$ streptozocin, Doxo doxorubicin, $5 F U$ 5-fluorouracil, $R R$ response rate, $q d$ once every day, $m P F S$ median progressionfree survival, $m O S$ median overall survival, $H R$ hazard ratio, $n s$ non-significant

(44-52\% 5-year overall survival (OS) rates) but may be considered in highly selected young patients ( $<55$ years) with well-differentiated liver-only metastases, resected primary tumor and low ki67 index $(<5 \%)$, who demonstrated a stable disease status for at least 6 months before organ transplantation [11] (IV, C).

\section{Locoregional therapy}

In patients who are not suitable candidates for surgery, regional control of liver metastases may be achieved (50-80\% 5-year OS in small retrospective series) by different ablative techniques such as laparoscopic or percutaneous radiofrequency or laser ablation, and cryotherapy, among others [12,13]. Other locoregional approaches include embolization of the hepatic artery by particles with or without cytotoxic agents (TACE/TAE) or radioactive microspheres (TARE). These therapies may be considered as an alternative approach to systemic therapies, especially for patients with symptomatic/functioning high liver tumor burden. Doxorubicin and mitomycin $\mathrm{C}$ are commonly used agents in this context, although adequately sized randomized studies that properly evaluate the benefit-risk ratio of chemoembolization with that of mechanical embolization are still lacking. Clinical responses have been reported in up to $80 \%$ of the patients, and radiological responses in about $50 \%$. Embolization is contraindicated in patients with portal-vein thrombosis, liver insufficiency, biliary obstruction or prior Whipple procedure. Radioembolization is an alternative technique of liver-directed therapy (most commonly with yttrium-90 microspheres) with similar clinical results, but prospective randomized trials comparing it to the other liverdirected modalities are lacking [14] (III, C).

\section{SSAs and interferon}

SSAs are the first choice of therapy for symptom control in functional GEP-NETs (70-80\% of patients experience resolution of diarrhea or flushing, and about $40 \%$ achieve biochemical response) (III, A) and they also have antiproliferative activity as demonstrated in two placebo-controlled randomized trials. (I, A) The PROMID study enrolled 85 patients with G1 metastatic midgut NETs, which were randomized to receive octreotide LAR (30 mg/28 days) or placebo. Time to tumor progression was significantly longer in the octreotide LAR group (14.3 months) as compared to patients treated with placebo (6 months) [HR 0.34; $95 \%$ confidence interval (CI) $0.20-0.59, p<0.001]$. The greatest 
effect was observed in patients with low hepatic tumor load and resected primary tumor [15]. No difference was observed, however, in OS among study arms. More recently, the CLARINET study [16] included 204 patients with nonfunctioning GEP-NETs and ki67 < 10\% (45\% pancreatic, $36 \%$ midgut, $7 \%$ hindgut and $13 \%$ of unknown primary), that were randomly allocated to receive lanreotide autogel (120 mg/28 days) or placebo [16]. Treatment with lanreotide significantly prolonged progression-free survival (PFS) over placebo (median not reached with lanreotide vs. 18 months with placebo, HR $0.47, p<0.001$ ). Of note, patients with high liver involvement ( $>25 \%$ ) also benefited from lanreotide. Currently recommended antiproliferative doses are octreotide LAR $30 \mathrm{mg}$ or lanreotide autogel $120 \mathrm{mg}$ every 28 days. Lower starting doses may be used for syndrome control, and then be titrated as needed. Short-acting subcutaneous octreotide may be necessary as rescue treatment for carcinoid syndrome exacerbations. Doses above $120 \mathrm{mg}$ for lanreotide autogel or $30 \mathrm{mg}$ for octreotide LAR are off-label but can sometimes be needed in selected cases. Adverse effects of SSA include malabsorption, hypo or hyperglycemia, hypothyroidism, pain and erythema at the site of injection, hypersensitivity reactions and cholelithiasis on long-term use.

Interferon has some activity in terms of symptomatic control of the hormonal syndrome, but adverse effects limit its widespread use (particularly fatigue, depression, liver toxicity, flu-like syndrome and myelosuppression). Although it may have some antiproliferative activity too, this has not been definitively proven [17], and it is therefore generally indicated after failure of other therapeutic options (III, C).

\section{Chemotherapy}

Systemic chemotherapy is indicated in progressive or bulky advanced panNETs and in G3 NENs. Chemotherapy may be considered in NETs of other sites (lung, thymus, stomach, colon, and rectum) in certain circumstances (e.g., ki67 in the upper $\mathrm{G} 2$ range, rapidly progressive disease and/or after failure of other therapies, particularly if somatostatin receptor imaging is negative). In patients with small intestinal primaries, chemotherapy plays a minor role and is generally reserved for patients with progressive disease along with other strategies (III, D).

Chemotherapy combinations most frequently used include streptozocin with either 5-FU or doxorubicin, with overall response rates (ORRs) of 45-69\% in older trials (II,B) and $28-42 \%$ in more recent ones, and PFS ranging from 16 to 23 months [18]. Other active agents include dacarbazine or temozolomide, Recently, results of a randomized phase II trial showed an increase in progression-free survival (PFS) (from 14.4 to 22.7 months, HR $0.58, p=0.023$ ) and in survival (38 months vs. not reached, HR 0.41, $p=0.012$ ) with similar response rates ( $27.8 \%$ vs. $33.3 \%)$ for the combination of temozolamide and capecitabine as compared to temozolamide alone in panNETs [19] (II, B).

No biomarkers may be currently recommended for routine clinical practice to predict response to chemotherapy. The use of MGMT deficiency as a predictive biomarker of temozolomide activity has not been demonstrated in prospective studies and is not considered standard.

No randomized studies have been performed in lung NETs (typical and atypical carcinoids). Chemotherapy is an option after failure of SSA and everolimus, or in patients with rapidly growing tumors. Temozolomide has been explored in non-randomized studies as well as in combination with oxaliplatin, with PFS ranging from 5 to 20 months [20] (III, B).

\section{Targeted agents}

Everolimus and sunitinib are approved worldwide for the treatment of advanced well-moderately differentiated NETs based on positive results of placebo-controlled phase III clinical trials. Sunitinib has demonstrated in an international, placebo-controlled phase III clinical study, significantly increased PFS in patients with advanced panNETs (median PFS 11.4 vs. 5.5 months; HR 0.42; 95\% CI $0.26-0.66, p<0.001$ ) (I, A). Recent updated data showed a trend towards an improved OS in favor of sunitinib, with almost 10 months median survival increase compared with placebo (38.6 vs. 29.1 months, HR 0.73; 95\% CI 0.50-1.06, $p=0.094$ ) [21]. The RADIANT-3 trial randomized patients with advanced well-moderately differentiated panNETs to receive everolimus or placebo demonstrating an increase of PFS in favor of everolimus (11.0 vs. 4.6 months; HR 0.35; 95\% CI 0.27-0.45, $p<0.001$ ). A follow-up reported no significant improvement in OS, but this may be attributed to the fact that $>70 \%$ of patients in the placebo arm crossed over to everolimus upon disease progression [22]. The RADIANT-4 trial confirmed the everolimus effectiveness in nonfunctioning NETs of lung or gastrointestinal origin. PFS was significantly increased with everolimus as compared to placebo (11.0 vs. 3.9 months, respectively, HR $0.48 ; 95 \%$ CI $0.35-0.67, p<0.00001$ ) [23]. The results obtained by the RADIANT- 3 and -4 trials led to the approval of everolimus by regulatory authorities for the treatment of advanced and progressive, well-moderately differentiated, functioning and non-functioning panNETs and for non-functioning gastrointestinal and lung NETs (I, A).

\section{Metabolic therapy}

Patients with advanced disease and a positive somatostatin-receptor imaging may be considered for peptide receptor radionuclide therapy (PRRT). PRRT primarily 
utilizes one of two radioisotopes, yttrium-90 $\left({ }^{90} \mathrm{Y}\right)$ or lutetium $177\left({ }^{177} \mathrm{Lu}\right)$, linked to a SSA via the chelating agent 1,4,7,10-tetraazacyclo-dodecane-1,4,7,10-tetraacetic acid (DOTA).

The phase III NETTER-1 study, conducted in patients with midgut NETs progressive to standard-dose SSA, has shown that lutetium $\left({ }^{177} \mathrm{Lu}\right)$-DOTATATE, compared to high doses of octreotide, significantly increases the ORR (18 vs. $3 \% ; p<0.001)$ and PFS (28.4 vs. 8.5 months; HR $0.21,95 \%$ CI $0.14-0.33, p<0.0001$ ), with a trend towards improved OS, although data are still immature for definitive conclusions in this regard (median not achieved vs. 27.4 months, HR 0.46 , 95\% CI 0.14-1.5). In addition, 177Lu-DOTATATE was able to improve the subjective measurement of patient's quality of life in multiple relevant domains, such as global health status, physical functioning, role functioning, fatigue, diarrhea, pain, disease-related worries and body image. With limited median follow-up, 14 months, the most common grade 3-4 toxicities were lymphopenia (9\%) and emesis (7\%), with no renal toxicity detected [24].

Large series from reference European centres have reported significant PRRT activity in NETs of primary tumor sites other than the midgut. In this series, the ORR was $30 \%$, PFS was 40 months, OS was 46 months. ORRs were higher in patients with gastrinomas, insulinomas, VIPomas and non-functioning panNETs than in carcinoid tumors. In multivariate analysis, uptake on the OctreoScan $(p<0.01)$, and Karnofsky performance status $>70 \%(p<0.05)$ were prognostic factors for predicting tumor remission [25].

Therefore, PRRT is indicated in patients with well-differentiated, metastatic, unresectable midgut NETs, in progression to SSA and with positive somatostatin receptors (grade
2-4 scale Krenning). It is also required for the patient to have a good performance status $(\mathrm{ECOG}<2)$, and an adequate renal, hepatic and bone marrow function. (I, A) Its administration to tumors of other primary sites may also be considered although the evidence to support it is not derived from randomized trials (II, B). The appropriate timing of this therapeutic intervention remains to be elucidated.

\section{Grade 3 NENs (Fig. 2)}

Malignancies with a ki67 $>20 \%$ and poor differentiation are considered G3 NEC. Well-differentiated tumors with a proliferation index $>20 \%$ are called G3 NET by the NEN community [although this category only applies to panNETs in WHO 2017 (Table 2)] [26].

Localized disease is usually managed with surgery (IV, C). However, retrospective series indicate that this approach alone is rarely curative and suggest improved results with adjuvant chemotherapy. Radiotherapy may be used as consolidation therapy in this scenario too, and as an alternative to surgery in certain primary sites (i.e., esophageal NECs) or in the setting of non-resectable locally advanced disease. However, the management of NECs with non-resectable or metastatic advanced disease is still based on systemic cytotoxic chemotherapy (III, B). Current treatments are based on data from small cell lung cancer, most commonly treated with cisplatin/carboplatin-etoposide. First-line treatment for NECs has remained unchanged since the early 1990s, when high ORRs were reported with etoposide-platinum combination (41-67\%). In addition, a number of small retrospective series have published results of other chemotherapy regimens (temozolomide-based, taxane-based, 5-FU-based, or

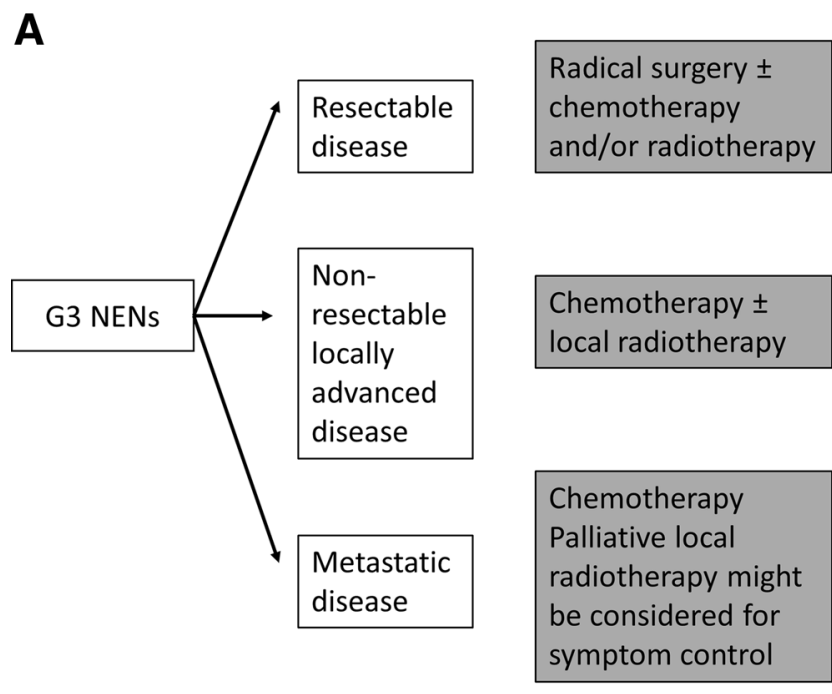

B

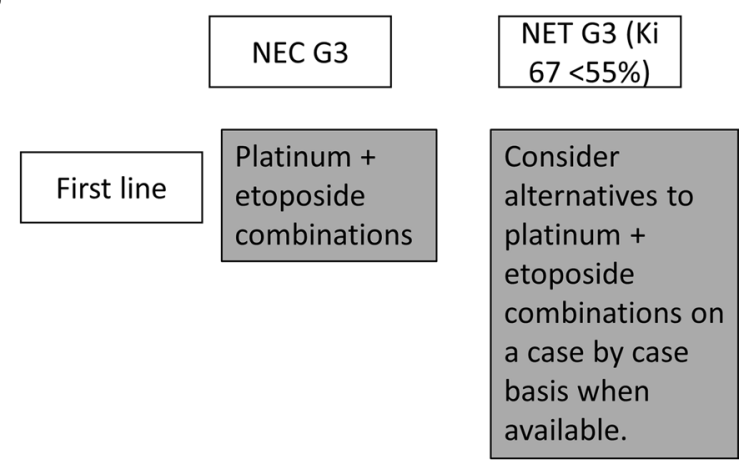

Second line
FOLFOX, FOLFIRI, Temozolomide plus Capecitabine are within the most used regimens. The latter is commonly used as first line for $\mathrm{G} 3$ NETs with Ki $67<55 \%$.

Fig. 2 Therapeutic algorythm for G3 NENs 
topotecan/irinotecan-based) after failure of platinum-etoposide therapy in patients with NECs (IV, C) [27].

The marginal benefit observed in two retrospective series with first-line platinum combination in NENs with ki67 between 20 and 55\% and in G3 NETs has led many doctors in specialized NET centres to recommend non-platinum combinations for this subgroup, such as temozolomide and capecitabine [28] (IV, C). This alternative, orally administered regimen has the added value of its improved tolerance.

\section{Follow-up}

There is no consensus regarding optimal follow-up of resected NENs. A web-based practice survey targeted at NET health care providers in Australia, New Zealand, Canada and the US illustrated the great variation among professionals in follow-up practices and highlights the need for quantitative research to provide solid evidence to base follow-up guidelines to the pattern of recurrence in NENs [29].

Based on expert opinion, resected well-differentiated G1-2 NENs shall be followed-up every 6-12 months for the first 2-3 years after surgery, and then every 12-24 months up to 10 years. Follow-up intervals shall be shorter in patients with G3 NECs (every 3-6 months during the first 3 years, every 6-12 months thereafter). This follow-up must include a clinical evaluation (especially in functioning tumors), a physical examination, biochemical markers and imaging techniques $(\mathrm{V}, \mathrm{C})$. General tumor markers may be considered in all patients (chromogranin A in G1-2 NETs or NSE in G3 NECs), even though their value in follow-up is still to be proven, and specific markers shall be performed only in patients with hormone syndromes (5HIAA, insulin, gastrin...) (III, B). Regarding imaging techniques, an abdominal CT scan or MRI is recommended to be performed at least annually during the first 3 years, and biannually thereafter up to 10 years following surgery $(\mathrm{V}, \mathrm{C})$. Chest imaging or functional imaging is not recommended unless clinically indicated but is mandatory in lung NEN patients.

There are certain low-risk subgroups in which no followup is required, such as small $(<2 \mathrm{~cm}) \mathrm{G} 1$ node-negative panNETs, node-negative insulinomas, incidental G1 T1-2 node-negative midgut NETs, small $(<1 \mathrm{~cm})$ G1 appendiceal NETs, and G1 T1 node-negative rectal NETs (V, C).

In patients with advanced disease who are receiving active therapy, follow-up visits will depend on the tolerability, expected toxicity, concomitant diseases, symptom control (including hormonal syndrome), tumor kinetics and response to treatment $(\mathrm{V}, \mathrm{C})$. Visits may be done every 6 months for G1, slow growing tumors, in clinically stable patients under low-toxic therapies (i.e., SSA). These intervals shall be shortened, however, for patients with faster tumor growth rates or receiving more toxic agents. Radiological evaluation of the disease should be done every 3-6 months, most commonly by CT scan. The global heart function must be controlled in cases of possible carcinoid cardiac disease. However, clinical judgement must be applied and each patient individually assessed.

\section{Compliance with ethical standards}

Conflict of interest EGF reports Advisory from Pfizer, Novartis, Ipsen and AAA, outside the submitted work. RS reports Advisory from Pfizer, Novartis and Ipsen, outside the submitted work. IS reports Advisory from Pfizer, Novartis and Ipsen, outside the submitted work. AV has nothing to disclose. JB reports Grants and travel expenses from Ipsen, Pfizer, Novartis and AAA, outside the submitted work. MB has nothing to disclose. JC has nothing to disclose. PJF has nothing to disclose. CL reports personal fees and non-financial support from Pfizer, personal fees and non-financial support from IPSEN, personal fees and non-financial support from NOVARTIS, outside the submitted work. RGC has received honoraria from Ipsen, Novartis, Pfizer and AAA.

Ethical approval The current study has been performed in accordance with the ethical standards laid down in the 1964 Declaration of Helsinki and its later amendments.

Informed consent For this type of study, no formal consent is required.

Open Access This article is distributed under the terms of the Creative Commons Attribution 4.0 International License (http://creativeco mmons.org/licenses/by/4.0/), which permits unrestricted use, distribution, and reproduction in any medium, provided you give appropriate credit to the original author(s) and the source, provide a link to the Creative Commons license, and indicate if changes were made.

\section{References}

1. Dasari A, Shen C, Halperin D, Zhao B, Zhou S, Xu Y, et al. Trends in the incidence, prevalence, and survival outcomes in patients with neuroendocrine tumors in the United States. JAMA Oncol. 2017;3:1335-42.

2. Nuñez-Valdovinos B, Carmona-Bayonas A, Jimenez-Fonseca P, Capdevila J, Castaño-Pascual A, Benavent M, et al. Neuroendocrine tumor heterogeneity adds uncertainty to the WHO 2010. Oncologist. 2018;22:1-11.

3. García-Carbonero R, Vilardell F, Jiménez-Fonseca P, GonzálezCampora R, González E, Cuatrecasas M, et al. Guidelines for biomarker testing in gastroenteropancreatic neuroendocrine neoplasms: a national consensus of the Spanish Society of Pathology and the Spanish Society of Medical Oncology. Clin Transl Oncol. 2014;16(3):243-56.

4. Werner RA, Bluemel C, Allen-Auerbach MS, Higuchi T, Herrmann K. 68Gallium- and 90Yttrium-/177Lutetium: "theranostic twins" for diagnosis and treatment of NETs. Ann Nucl Med. 2015;29(1):1-7.

5. Rindi G, Petrone G, Inzani F. The 2010 WHO classification of digestive neuroendocrine neoplasms: a critical appraisal four years after its introduction. Endocr Pathol. 2014;25:186-92.

6. Klöppel G, Klimstra DS, Hruban RH, Adsay V, Capella C, Couvelard A, et al. Pancreatic Neuroendocrine tumors: update on 
the New World Health Organization Classification. AJSP Rev Rep. 2017;22(5):233-9.

7. Klöppel G. Neuroendocrine neoplasms: dichotomy, origin and classifications. Visc Med. 2017;33:324-30.

8. Zheng M. Classification and pathology of lung cancer. Surg Oncol Clin N Am. 2016;25(3):447-68.

9. Capdevila J, Castellano D, Díaz Pérez JA, Escudero P, Navarro L, Segura Á, Grande E, Salazar R, Sevilla I, López G. Guía práctica de diagnóstico, tratamiento y seguimiento de Tumores Neuroendocrinos. 3a Edición. Barcelona: Edika Med SL; 2016.

10. Yuan CH, Wang J, Xiu DR, Tao M, Ma ZL, Jiang B, et al. Meta-analysis of liver resection versus nonsurgical treatments for pancreatic neuroendocrine tumors with liver metastases. Ann Surg Oncol. 2016;23(1):244-9.

11. Vilchez V, Gedaly R. Liver transplantation for the treatment of neuroendocrine liver metastases. Best Pract Res Clin Endocrinol Metab. 2016;30(1):141-7.

12. Akyildiz HY, Mitchell J, Milas M, Siperstein A, Berber E. Laparoscopic radiofrequency thermal ablation of neuroendocrine hepatic metastases: long term follow-up. Surgery. 2010;148(6):1288-93.

13. Yang TX, Chua TC, Morris DL. Radioembolization and chemoembolization for unresectable neuroendocrine liver metastases-a systematic review. Surg Oncol. 2012;21(4):299-308.

14. Kennedy A, Bester L, Salem R, Sharma RA, Parks RW, Ruszniewski P. Role of hepatic intra-arterial therapies in metastatic neuroendocrine tumours (NET): guidelines from the NET-Liver Metastases Consensus Conference. HP (Oxf). 2015;17(1):29-37.

15. Rinke A, Müller HH, Schade-Brittinger C, Klose KJ, Barth P, Wied M, et al. Placebo-controlled, double-blind, prospective, randomized study on the effect of octreotide LAR in the control of tumor growth in patients with metastatic neuroendocrine midgut tumors: a report from the PROMID Study Group. J Clin Oncol. 2009;27:4656-63.

16. Caplin ME, Pavel M, Ćwikła JB, Phan AT, Raderer M, Sedláčková $\mathrm{E}$, et al. Lanreotide in metastatic enteropancreatic neuroendocrine tumors. N Engl J Med. 2014;371(3):224-33.

17. Yao JC, Guthrie KA, Moran C, Strosberg JR, Kulke MH, Chan JA, et al. Phase III prospective randomized comparison trial of depot octreotide plus interferon alfa-2b versus depot octreotide plus bevacizumab in patients with advanced carcinoid tumors: SWOG S0518. J Clin Oncol. 2017;35(15):1695-703.

18. Clewemar Antonodimitrakis P, Sundin A, Wassberg C, Granberg D, Skogseid B, Erikson B. Streptozocin and 5-fluorouracil for the treatment of pancreatic neuroendocrine tumors: efficacy, prognostic factors and toxicity. Neuroendocrinology. 2016;103:345-53.

19. Kunz PL, Catalano PJ, Nimeiri H, Fisher GA, Longacre TA, Suarez CJ, et al. A randomized study of temozolomide or temozolomide and capecitabine in patients with advanced pancreatic neuroendocrine tumors: A trial of the ECOG-ACRIN Cancer Research Group (E2211). J Clin Oncol. 2018;36 (suppl; abstr 4004).

20. Fazio N, Ungaro A, Spada F, Cella CA, Pisa E, Barberis M, et al. The role of multimodal treatment in patients with advanced lung neuroendocrine tumors. J Thorac Dis. 2017;9(suppl 15):S1501-10.

21. Faivre S, Niccoli P, Castellano D, Valle JW, Hammel P, Raoul $\mathrm{JL}$, et al. Sunitinib in pancreatic neuroendocrine tumors: updated progression-free survival and final overall survival from a phase III randomized study. Ann Oncol. 2017;28(2):339-43.

22. Yao JC, Shah MH, Ito T, Bohas CL, Wolin EM, Van Cutsem E, et al. Everolimus for advanced pancreatic neuroendocrine tumors. N Engl J Med. 2011;364(6):514-23.

23. Yao JC, Fazio N, Singh S, Buzzoni R, Carnaghi C, Wolin E, et al. Everolimus for the treatment of advanced, non-functional neuroendocrine tumours of the lung or gastrointestinal tract (RADIANT-4): a randomised, placebo-controlled, phase 3 study. Lancet. 2016;387(10022):968-77.

24. Strosberg J, El-Haddad G, Wolin E, Hendifar A, Yao J, Chasen B, et al. Phase 3 trial of $177 \mathrm{Lu}$-dotatate for midgut neuroendocrine tumors. N Engl J Med. 2017;376:125-35.

25. Imhof A, Brunner P, Marincek N, Briel M, Schindler C, Rasch $\mathrm{H}$, et al. Response, survival, and long-term toxicity after therapy with the radiolabeled somatostatin analogue (90Y-DOTA)TOC in metastasized neuroendocrine cancers. J Clin Oncol. 2011;29(17):2416-23.

26. Heetfeld M, Chougnet CN, Olsen IH, Rinke A, Borbath I, Crespo $\mathrm{G}$, et al. Characteristics and treatment of patients with G3 gastroenteropancreatic neuroendocrine neoplasms. Endocr Relat Cancer. 2015;22:657-64.

27. Lamarca A, Walter T, Pavel M, Borbath I, Freis P, Nuñez B, et al. Design and validation of the GI-NEC score to prognosticate overall survival in patients with high-grade gastrointestinal neuroendocrine carcinomas. J Natl Cancer Inst. 2017;109(5):djw277. https ://doi.org/10.1093/jnci/djw277.

28. Sorbye H, Welin S, Langer SW, Vestermark LW, Holt N, Osterlund $\mathrm{P}$, et al. Predictive and prognostic factors for treatment and survival in 305 patients with advanced gastrointestinal neuroendocrine carcinoma (WHO G3): the NORDIC NEC study. Ann Oncol. 2013;24:152-60.

29. Chan DL, Moody L, Segelov E, Metz D, Strosberg J, Pavlakis N, et al. Follow-up for resected gastroenteropancreatic neuroendocrine tumours (GEP-NETs): a practice survey of the Commonwealth Neuroendocrine collaboration (CommNETs) and North American Neuroendocrine Tumor Society (NANETS). Neuroendocrinology. 2018;107(1):32-41. 